\title{
A CASA VAZANTEIRA: BICHOS, PLANTAS, VAZANTES E PROJETOS DE DESENVOLVIMENTO URBANO NAS MARGENS DO RIO PARNAÍBA
}

\author{
Lucas Coelho Pereira ${ }^{1}$
}

\section{Introdução}

"Vazanteiros" é como se denominam agricultores que cultivam nas margens e ilhas dos rios. "Vazantes" falam tanto do lugar onde esses cultivos são realizados quanto dos próprios cultivares. Trata-se de uma atividade agrícola amplamente desenvolvida em diversas regiões do país. Diegues e Arruda (2001) citam vazanteiros com a denominação de "varjeiros" e os definem como populações tradicionais residentes nas proximidades de rios e várzeas.

$\mathrm{Na}$ literatura socioantropológica, alguns trabalhos se dedicaram a pensar o modo de vida desses grupos sociais. Principalmente os seus dilemas frente a projetos de desenvolvimento que impactam direta e negativamente suas atividades e territórios tradicionais (Almeida Costa e Luz de Oliveira, 2012; Anaya, 2012; Castro, 2017; Castro et al., 2018; Luz de Oliveira, 2005). De alguma forma, me conecto a essas investigações. Irei falar de vazanteiros que há décadas vivem um processo de desterritorialização causado por uma política de requalificação urbana.

Acompanharemos famílias residentes no curso médio do Rio Parnaíba, em Teresina-PI, na Avenida Boa Esperança. Pessoas diretamente afetadas pelo Programa Lagoas do Norte, obra financiada pelo governo federal através do Programa de Aceleração do Crescimento (PAC), com recursos do Banco Mundial e levada a cabo pela Prefeitura Municipal de Teresina. Minha preocupação central, contudo, é perceber este conflito territorial e socioambiental (Little, 2002, 2006; Lopes, 2004) a partir do modo como vazanteiros e vazanteiras constituem suas casas. Procurarei atentar para a multiplicidade de viventes humanos e não humanos presentes nesses ambientes.

Desenvolverei, assim, o que seria uma teoria etnográfica da noção de casa para famílias de vazanteiros e vazanteiras da Avenida Boa Esperança ${ }^{2}$. Inspirado nas discussões de Haraway (2003; 2008), Tsing (2015a) e Ingold (1996; 2000; 2015)

\footnotetext{
${ }^{1}$ Universidade de Brasília (PPGAS/DAN/UnB), Brasília, Brasil. E-mail: lucascoelhopereira@gmail.com ORCID: https://orcid.org/0000-0001-8634-045X

${ }^{2}$ Desenvolvo pesquisas e trabalhos de assessoria técnica popular na zona norte da cidade de Teresina desde 2011. O campo que embasa etnograficamente este artigo, em específico, foi feito entre os anos de 2015 e 2016.
} 
procurarei pensar sobre os seres atuantes no sentido de se constituir uma casa na vazante. A ideia é discutir como esta noção tem sido trabalhada na antropologia e - em diálogo com a proposta metodológica das etnografias multiespécie ${ }^{3}$ - repensá-la. Argumento que, a partir das vazantes do Parnaíba, casa englobaria não apenas seus habitantes humanos, mas um sem número de bichos e plantas, bem como extensões territoriais adjacentes como os quintais e as próprias vazantes. Casa e vazante, portanto, são articuladas como duas instâncias de um mesmo espaço e movimento, a saber, habitar um lugar a partir da construção de uma residência.

É exatamente este processo que a política de urbanização empreendida pelo Programa Lagoas do Norte ignora. No lugar das residências de vazanteiros e vazanteiras, serão erguidos hotéis, centros de convenções e parques de lazer e turismo.Uma casa em outro lugar da cidade e sem a possibilidade de continuarem a cultivar suas vazantes é oferecida como contrapartida. Mas seria mesmo essa casa ofertada pelo Programa Lagoas do Norte uma "casa de verdade" na perspectiva de vazanteiros e vazanteiras? Essa pergunta nos leva para o cerne de um conflito territorial e socioambiental urbano aqui pensado através do que (e como) se constitui (ou não) uma casa.

No primeiro tópico, apresento a região da Avenida Boa Esperança e as dinâmicas urbanas que lhe constituíram. Discorro sobre isso através da trajetória de dona Davina e seu falecido marido. Mostro como edificar uma casa e cultivar nas vazantes do rio Parnaíba são processos conjuntos de um mesmo movimento de habitação empreendido por essa e outras famílias de vazanteiros/as. O que envolve se engajar com uma multiplicidade de coisas e seres.

No segundo tópico, apresento os viventes e não viventes que compõem as dinâmicas da vazante e da rede de cuidados e práticas que conectam - em um mesmo continuum habitacional/espacial - casa e vazantes. Faço isso para, na seção seguinte,

\footnotetext{
${ }^{3}$ Dialogando com a premissa de não centralidade da agência humana, a etnografia multiespécie procura colocar em suspenso o "antropo" e observar mais detidamente tudo aquilo que ele se recusa a reconhecer. Para Tsing (2015b), o foco exclusivo no humano bloqueia a nossa atenção para as múltiplas temporalidades, paisagens e acoplamentos entre humanos e não humanos que possibilitam a existência dos seres em uma rede extremamente colaborativa. Reconheço que abordagens holísticas e ecológicas do mundo social não são lá muita novidade na disciplina (Boas, 2004; Evans-Prictchard, 1978). Os enfoques e métodos utilizados nestas abordagens, contudo, têm variado no decorrer dos tempos e das antropologias. A etnografia multiespécie, por sua vez, pretende dar mais foco a esses outros elementos que compõe os ambientes, centrada muito mais nas relações estabelecidas entre os diversos seres mais-que-humanos do que, propriamente, no foco privilegiado da maioria das análises sócio-antropológicas: o humano. A investigação recai, portanto, em como esses seres constituem a si mesmos e a outros a partir das relações que estabelecem, evidenciando a multiplicidade de atores e espécies em interação.
} 
desenvolver o que seria a ideia de uma "casa multiespécie", levando a sério as práticas de habitação empreendidas por vazanteiros e vazanteiras da região. Na quarta seção, analiso documentos emitidos pelo Programa Lagoas do Norte, a fim de explicitar a concepção de casa articulada por esse projeto de desenvolvimento urbano. Destaco as incomensurabilidades entre esta noção de habitar e aquela articulada a partir das vazantes, além de desenvolver sobre como vazanteiros e vazanteiras reagiram diante da possibilidade de serem desapropriados/as. Por fim, teço algumas considerações sobre como este conflito territorial e socioambiental urbano é melhor apreendido se acompanharmos etnograficamente o que constitui uma casa para os diferentes atores envolvidos na questão.

\section{Habitando na Avenida: casa, olarias e vazantes}

Dona Davina, mulher negra e idosa, nasceu no município de José de Freitas interior do Piauí - e foi para Teresina ainda jovem e solteira, na faixa dos 20 anos de idade, morar com uma das suas irmãs. Em Teresina, Davina conheceu Antônio Ferreira de Sousa, seu Roxo, vaqueiro profissional e emigrado do estado de Pernambuco. Com ele Davina casou-se e constituiu família. Tiveram nove filhos e residiram em pelo menos três bairros diferentes na zona norte da cidade, sempre acompanhando o lugar de trabalho de Roxo.

As vacarias ${ }^{4}$ onde seu marido trabalhava eram também o local de residência da família, "mas essas casas não são nossas, Roxo, a gente tem que construir nossa casa", dizia dona Davina. Depois de pedir demissão de uma vacaria localizada no bairro Mafrense, Roxo, Dona Davina e seus seis filhos nascidos até então começaram a construção de uma casa que, inicialmente, era só um barraco onde hoje reside Dona Davina na Avenida Boa Esperança.

A Avenida Boa Esperança localiza-se na zona norte que, conforme Lima (2010), congrega alguns dos bairros mais antigos de Teresina e apresenta uma das maiores concentrações demográficas da cidade. Esse boom populacional na região teria ocorrido na década de 1970, quando o fluxo migratório campo-cidade intensificou-se consideravelmente. Assim, a expansão urbana para esta área relaciona-se com os baixos preços da renda da terra e dos aluguéis. O que atraiu muitos migrantes (Lima, 2010).

${ }^{4}$ Estabelecimento destinado à criação e abate de gado bovino para comercialização. 
De acordo com Moraes (2013), o aumento populacional na Zona Norte - durante as décadas de 1960 e 1970 - pode ainda ser atrelado a um fator bem específico, a saber, o crescimento do setor de construção civil na cidade. Neste momento, pessoas oriundas de bairros mais abastados de Teresina apossaram-se de alguns pedaços de terra, tornando-se "donos de olaria", tendo em vista a grande ocorrência de jazidas minerais de argila na região. Esses ricos proprietários externos utilizavam-se indiscriminadamente e sem qualquer proteção trabalhista da mão-de-obra de moradores e moradoras locais. Algumas pessoas do lugar até chegaram a possuir barreiros (jazidas de extração de argila) próprios. Lugares nos quais trabalhavam junto com a família na produção de tijolos. A posse de barreiros por pessoas de maior poder aquisitivo, contudo, - inclusive congregando-se na Associação dos Oleiros de Teresina (ASSOUTER) - era $^{5}$, de longe, prática preponderante na zona norte da cidade (Portela, 2005).

Boa parte da zona norte encontra-se na porção de território urbano localizada entre a confluência dos rios Parnaíba e Poti. Além dos rios, autoras como Portela (2005) e Moura (2006) destacam ainda a forte presença de lagoas nesta área da cidade, que contabilizavam cerca de 34 no início dos anos 2000. A construção de barreiros para a retirada de argila no leito do rio Poti ocorria, principalmente, nas margens destes corpos hídricos.

Foi nesse contexto que dona Davina e seu marido, hoje falecido, foram aos poucos comprando madeiras e tijolos para a construção da residência própria. Nessa época - meados da década de 1950 - as casas ainda eram poucas no que mais tarde viria a ser a Avenida. O sustento da família advinha das vazantes cultivadas por eles e elas; de uma roça que seu Roxo fazia no povoado Boca da Mata, no Maranhão; da horta plantada por dona Davina no quintal; além da renda obtida com o trabalho de Roxo e seus filhos nas olarias da região.

Hoje, a casa de dona Davina é sempre agitada pelo entra e sai de filhos, netos, sobrinhos e amigos. Possui um terraço imenso, repleto de plantas e flores. Tudo cultivado por ela e por suas filhas, que a auxiliam cotidianamente nesta e em outras

\footnotetext{
${ }^{5}$ Atualmente, por conta das ações do Programa Lagoas do Norte, empreendido pelo poder público municipal em parceria com o Banco Mundial e o Governo, a extração de barro para a feitura de tijolos foi proibida desde o início dos anos 2000. Por ora, ainda é permitida a retirada de argila para a produção de artesanatos, em virtude de ser considerada por técnicos e funcionários da prefeitura como de menor vulto. Neste contexto, emergem diversas controvérsias no que diz respeito à definição - por parte da prefeiturade um novo local de extração de argila. Assim, se a extração de argila ainda segue sendo permitida, isto só ocorre pelo fato de a Prefeitura Municipal de Teresina não ter conseguido equacionar a própria proposta de encontrar outra área para extração do barro.
} 
atividades domésticas. O terraço é coberto por telhas, exceto na parte onde ficam as plantas.Na porção coberta, próximo à parede da sala, há uma prateleira de mármore com várias imagens de santos e santas do panteão católico. "A mamãe é muito apegada com os santos dela", disse-me certa vez Miúda, sua filha e principal cuidadora.

Boa parte da vida da casa, contudo, desenrola-se entre a cozinha e o quintal, onde há uma diversidade de árvores. A maioria delas frutíferas: mamoeiros, goiabeiras, um cajueiro, além de algumas pequenas palmeiras. São nessas porções do ambiente doméstico onde as pessoas da casa permanecem a maior parte do tempo a conversar em cadeiras de espaguetes, comer frutas e falar da vida... Além das pessoas, é impossível falar do quintal sem observar os outros organismos que o habitavam. Galinhas, galos, cachorros, papagaio e um casal de cabras, que viviam presas em pequeno curral.

A casa de dona Davina e diversas outras vazanteiras e vazanteiros compreende uma série de conexões estabelecidas a partir do quintal. No ato de cultivar hortaliças, criar animais e plantar árvores frutíferas neste espaço do lar, o próprio lugar vai sendo gestado.Além das convivencialidades ocorridas no quintal, as práticas desenvolvidas por dona Davina e sua família colocam em evidência uma série de dinâmicas que acompanharam o próprio processo de constituição urbana teresinense. Falo especificamente da atividade vazanteira.

O cultivo nas vazantes, também conhecido como "agricultura de vazantes" ou "vazante" caracteriza-se pelo plantio de leguminosas e verduras nas margens de rios, açudes e igarapés. Os resíduos minerais transportados pelas águas fazem desses ambientes terreno propício para uma ampla variedade de cultivares. O que é visto com bons olhos por quem cultiva, conforme ainda falarei adiante.Vazante, assim, significa tanto o próprio cultivo quanto às áreas cultiváveis próximas aos cursos d'água (Castro et al, 2018).

Pierson (1972), ao trazer relatos sobre as relações entre as pessoas e o rio São Francisco, falou de agricultores vazanteirosautoreconhecidos como "lameiros". Assim chamados por cultivarem nos barrancos de lama deixados pelo rio em suas coroas e margens.Na antropologia, ainda são poucos os trabalhos que tematizam o modo de vida deste segmento. Destaco as etnografias de Luz de Oliveira (2005), sobre as territorialidades constituídas por vazanteiros do Rio São Francisco e Castro (2017), cuja pesquisa, entre outras coisas, dedica-se a descrever os sistemas agrícolas de agricultores vazanteiros às margens do rio Tocantins.Ambos os trabalhos destacam os impactos 
socioambientais de mega-empreendimentos hidroelétricos nos territórios tradicionalmente ocupados por esses coletivos. Apresentam como vazanteiros e vazanteiras possuem relações profundas e diferenciadas com os lugares onde habitam, destacando a importância e complexidade das relações desenvolvidas por esses grupos sociais com seus ambientes de vida e trabalho.

Como já mencionado, o presente trabalho se aproxima de abordagens assim. Os vazanteiros da Avenida Boa Esperança - curso médio do rio Parnaíba - vivem, desde o início dos anos 2000, as consequências de um projeto de "revitalização" urbana que tem culminado na desapropriação compulsória de famílias de vazanteiros/vazanteiras, mas não só. Diversas outras comunidades tradicionais residentes na zona norte da cidade de Teresina, como pescadores e povos de terreiro (Amorim, 2010; Centro de Defesa Ferreira de Sousa, 2016; Carmo, 2017; Carmo e Morais, 2016; Monte, 2016; Coelho Pereira, 2017), também tem sofrido as consequências nefastas dos "reassentamentos involuntários"6. É, portanto, a partir desse contexto, que irei falar da relação intrínseca entre as casas de vazanteiros e vazanteiras, seus quintais e, sobretudo, suas vazantes.

\section{Relações entre humanos e outros viventes na vazante}

O fundo do quintal de dona Davina é cercado em todo o seu perímetro por um muro de tijolos. Há um portãozinho de grades, geralmente fechado com um cadeado. Ele dá acesso à vazante cultivada por ela e seus filhos. Dona Davina, assim como boa parte de suas vizinhas vazanteiras, não possui bombas de irrigação ${ }^{7}$ e isso só a permite cultivar com maior vigor no período do inverno ${ }^{8}$, quando as chuvas são fartas e as porções de terra na beira do rio estão constantemente úmidas. Os tempos ecológicos de

\footnotetext{
${ }^{6}$ Utilizo reassentamento involuntário entre aspas por se tratar de uma expressão do poder público municipal para designar o processo de desapropriação das famílias a serem afetadas pelo Programa Lagoas do Norte.

${ }^{7}$ Durante meu período de campo, observei que homens vazanteiros possuíam mais acesso a certas tecnologias agrícolas do que as mulheres. Eles cultivavam suas vazantes durante o ano inteiro e em maior escala, destinando boa parte dos legumes à comercialização e contando com o auxílio de bombas irrigação. As mulheres vazanteiras, por sua vez, não contavam com este recurso e ficavam bastante dependentes do período das chuvas para realizarem seus plantios, cultivando quase que exclusivamente para o consumo doméstico.

${ }^{8} \mathrm{Com}$ os/as vazanteiros aprendi que o ano se divide em "inverno" e "verão". O primeiro, reconhecido como o tempo das águas, compreenderia os meses de janeiro a maio/junho e o segundo, mais quente e seco,de junho/julho a meados de dezembro. Vale ressaltar, como pontuou a professora Dione Morais (DCS/UFPI) em comunicação pessoal, que a classificação inverno/ verão aqui apontada não é universal. Em diferentes lugares do Brasil, os meses correspondentes a cada um desses períodos variam consideravelmente. Destarte, embora essa delimitação vigore em grande parte do nordeste brasileiro, há certas diferenças quanto aos meses de chuva e estiagem no próprio estado do Piauí, caso coloquemos em comparação semi-árido e cerrados, por exemplo.
} 
verão e inverno dialogam com uma série de atividades nas vazantes da Boa Esperança. É o inverno que traz a umidade necessária para os legumes brotarem. E essa umidade só é possível graças às chuvas, que fazem transbordar o Parnaíba e deixam os baixões cobertos de água.

Conversando com vazanteiros e vazanteiras como Davina, aprendi que terra boa é terra coberta de lama.As chuvas, quando muito intensas, podem até matar parte de um cultivo já iniciado, mas a morte desses vegetais é considerada ínfima - pelos/as vazanteiros/as - quando comparada com a quantidade imensa de legumes que vingarão na terra com o baixar das águas. Porque as águas, longe de serem consideradas uma catástrofe em si, trazem consigo um imenso potencial de renovação do solo.

Desde antes da fundação da cidade, datada de 1852, famílias ribeirinhas residentes no que, hoje, chamamos Avenida Boa Esperança, cultivam suas vazantes nas margens do Parnaíba. Esse processo provoca o que seu Valdir - vizinho de dona Davina e de quem falarei mais adiante - chama de "cansaço da terra". Depois de tanto plantio, ela cansa, disse ele. A terra, portanto, não é uma simples depositária de sementes, mas apresenta uma série de qualidades cuidadas e observadas pelos/as vazanteiros/as em suas interações com ela.

O chão das vazantes é constituído como um ente dotado de características muito específicas, como "força" e "fraqueza", por exemplo ${ }^{9}$ O cansaço, nessa perspectiva, contudo, significa menos um estado fixo e mais um momento no ritmo das vidas e tempos ecológicos formadores das vazantes. Com as chuvas, o cansaço da terra pode ser literalmente lavado, contou seu Valdir, pois as águas molham o solo e, quanto mais tempo passam empossando os baixões, mais força e vigor trazem. Invernos rigorosos são prenúncios de uma vazante farta.

As cheias, nesse contexto, trazem a fertilidade e a satisfação de olhar pela janela e ver uma imensidão verde de legumes. O prazer de cultivar e de estar próxima do rio era constantemente comunicado na voz calma de dona Davina: "eu gosto da minha vazante... De plantar minhas coisinhas...".

O cultivo de vazantes na beira da Avenida Boa Esperança, isto é, nas margens e ilhas do Parnaíba, caracteriza-se pelo plantio de macaxeira, feijão, maxixe, pimenta-decheiro e, sobretudo, quiabos.O ato de plantar legumes na beira do rio implica em um constante processo de interação entre humanos e outros viventes.

\footnotetext{
${ }^{9}$ Essa classificação dos solos já foi reportada por outras pesquisas entre sociedades camponesas Brasil a fora (Woortmann e Woortmann, 1997; Woortmann, 2008, Costa Filho, 2008).
} 
As capivaras, por exemplo, são animais incômodos aos vazanteiros e, cada um ao seu modo, vai co-habitando nas vazantes com elas. Alguns fazem espantalhos com roupas velhas e capacetes de motocicleta. Outros cercam porções de terra para impedirlhes o acesso. Há ainda aqueles/as que procuram plantar um pouco mais distante do rio. Além das capivaras, é possível observar uma diversidade de aves a circular pelas plantações. Anuns, severinos, pardais, rolinhas, bem-te-vis. Esses pássaros não chegam a ser focos de conflitos e perseguições (Virgílio, 2014) na vida dos vazanteiros com quem convivi. Porém não posso falar o mesmo dos pombos. Repetidas vezes, seu Valdir reclamou-se deles para mim:

- A gente tem que tomar um cuidado danado... Eu tive que replantar umas dez covas de feijão semana passada, porque os pombos chegam, vão revirando a terra e comem as sementes todinhas. Quando eu olho assim para a cova, já sei se eles mexeram...

É neste sentido que ter uma vazante, como me pontuaram seu Valdir e outros vazanteiros, implica numa constante luta com uma diversidade de outros seres. Repito: não uma luta contra, mas uma luta com outros através da qual a vida é gestada. Constituir-se e constituir ambientes com - tal qual apontado também por Virgílio (2014) através da noção de peleja - envolve uma série de lutas e interações nem de longe passíveis de serem consideradas idílicas e harmoniosas. Esses processos, da forma como foi captado por mim entre os vazanteiros da Boa Esperança, não passam pela noção de um enfrentamento dos "homens" versus a "natureza" (Brandão, 1999), onde os primeiros devem triunfar, vencer, ganhar e, por fim, exercer seu domínio sobre a última. A luta, antes disso, é um movimento de percepção a respeito dos modos de habitação (Ingold, 2000) empreendidos por outros seres, que não apenas humanos. Pelejar, trabalhar, enfim, lutar com bichos e plantas é, portanto, habitar e constituir ambientes em diálogos com "outros significantes” (Haraway, 2008; 2003).

Esta noção acionada por Donna Haraway me orientou o olhar para pensar humanos, plantas e animais a partir das relações que estabelecem. Sem fixá-los a priori em domínios ontologicamente distintos e pré-determinados, mas, antes de tudo, acompanhando as histórias de emaranhamentos e conexões entre eles. Lidar com "outros significantes", a meu ver, implica em desorbitar a oposição entre certos binarismos, como natureza e cultura, por exemplo, para acompanhar como sujeitos diversos vão se constituindo mutuamente em situações específicas. O que significa, por 
um lado, considerar a complexidade de relações nem sempre harmônicas e simétricas e, por outro, fugir de narrativas que têm o humano como foco privilegiado.

Não se trata, contudo, de deixar de lado o componente humano, mas apenas de não o entender como o único ser dotado de agência. A ideia é desviar o foco para os engajamentos e interações estabelecidas. Ao pensar a relação entre vazanteiros, legumes e capivaras através desta perspectiva, por exemplo, corro de interpretações que colocam humanos como detentores do poder cultural de dominar e, assim, domesticar plantas e animais para o objetivo único de se auto beneficiar. Longe disso, penso com Haraway que a própria domesticação é um processo de co-habitação e co-evolução, envolve agências de diversos tipos e variáveis que não podem ser facilmente revertidas num resultado certeiro para quem quer que seja (Haraway, 2003: 30) ${ }^{10}$.

Ao olhar para a relação entre cachorros e humanos, Donna Haraway está atenta para tudo o que floresce nessa interação, inclusive relações coloniais, agonísticas e de mortes, por exemplo. Ela nos orienta a olhar para o mundo considerando o que está em jogo para todas as partes envolvidas, humanas e não-humanas. Assim, adentrar o universo das relações e experimentações mútuas entre humanos e animais implica deixar-se envolver em tramas de relacionamentos que - assim como quaisquer outras não são necessariamente boas ou más, mas repletas “de desperdício, crueldades, indiferenças, ignorância, bem como de alegria, divertimento, invenção, trabalho, inteligência e brincadeira (Haraway, 2003: 12).

É neste sentido que a ideia de co-evolução - citada pela autora - envolve basicamente esse emaranhado de relações entre seres que se influenciam reciprocamente nos mais variados níveis, do social ao biológico. Das análises de Haraway infere-se que a própria história da humanidade é um complexo de relações inter-específicas ou, mais fidedignamente, de relações entre "espécies companheiras". Isto é, espécies que compartilham dos mesmos contextos e vão se constituindo a partir de suas interações.

\footnotetext{
${ }^{10}$ Durante muito tempo a antropologia "abriu mão" do "mundo natural", relegando certos aspectos do mundo da vida para outras áreas - como química, física e biologia, por exemplo - preocupando-se apenas com questões consideradas da ordem do "simbólico" ou "cultural" (Ingold, 1996; 2000). Perspectivas assim, compartilham da abordagem geertziana de que a antropologia seria uma ciência interpretativa à procura de significados.Ao observar comportamentos animais ou ciclos do desenvolvimento de um vegetal específico, o trabalho do antropólogo seria “desvendar" os símbolos e sentidos acionados pelos humanos ao se relacionarem com isso. Adotando um prisma diferente, Ingold (2015) destaca o caráter experimental do conhecimento antropológico. Isso significa, antes de tudo, seguir o fluxo das experimentações cotidianas feitas pelas pessoas na busca de respostas para suas questões. Experimentar junto. Envolver-se nas situações práticas dos nossos anfitriões a fim de perceber como certos dilemas de vital importância são gestados. A meu ver, essa dica metodológica de Ingold conecta-se com as reflexões de Donna Haraway descritas acima.
} 
Longe de significarem apenas os "animais de companhia" - como cachorros, cavalos, gatos e etc. - este termo envolve uma gama de outros seres que também se relacionam e se constituem com humanos de variadas formas - como abelhas, besouros, capivaras, pombos, fungos e plantas, por exemplo.

No caso das vazantes, diversos seres precisam ser atendidos no processo de cultivo dos legumes: tem-se que estar atento ao fogo que, eventualmente, pode queimar todo um plantio de cana; há os animais dos/as vizinhos/as a entrar nas plantações destruindo pés de quiabo, comendo vagens de feijão e pisoteando tantos outros legumes. É preciso ainda lidar com insetos, capivaras, pombos, camaleões, ervas daninhas e a irrigação dos cultivos. Os canos, aspersores, cabos de eletricidade e bombas hidráulicas custam caro e podem muito facilmente ser furtados. Tem-se que atentar para isso também ${ }^{11}$. Nesta lógica de cuidados e relações com a terra, cultivar uma vazante inevitavelmente significa residir nas suas proximidades, como me pontuara seu Valdir. Fazer casa e cultivar vazantes, portanto, são dois movimentos de um mesmo processo. Um está intrinsecamente relacionado com o outro de forma que é difícil precisar, no caso de famílias vazanteiras, os limites entre ambos.

\section{A casa vazanteira}

Brum e Vilar (2019), em um recente dossiê sobre "casa", destacam o quanto esse tema tem ganhado diversos enfoques nas ciências sociais. Elas lembram, por exemplo, a análise de Lévi Strauss (1957) sobre a casa Bororo e o texto clássico de Pierre Bourdieu a respeito da casa kabyle (1999). Fugindo de abordagens preocupadas unicamente com a dimensão material das habitações - com ênfase no tamanho, forma e matérias primas utilizadas - as autoras destacam o quanto a antropologia tem contribuído para se pensar casa em diálogo com seus sentidos e funções nos contextos em que são construídas. $\mathrm{O}$ que tem levado a disciplina a refletir sobre este fenômeno para além do universo privado de indivíduos e grupos, percebendo, inclusive, suas (re) elaborações em dinâmicas de migração transnacional (Nogueira e Silva, 2019).

Para além das relações estabelecidas entre humanos na constituição do espaço doméstico, quero adicionalmente chamar atenção para a multiplicidade de outros seres

\footnotetext{
${ }^{11}$ Para os vazanteiros que possuem equipamentos hidráulicos de irrigação, cultivar uma vazante implica cuidados a mais. É preciso estar atento aos irrigadores que devem ser colocados e retirados cotidianamente das vazantes.
} 
que também habitam neste ambiente. $\mathrm{O}$ que dizer dos cachorros, papagaio e plantas presentes na residência de dona Davina? Como entender o próprio ambiente das vazantes constituindo o que esta senhora e seus vizinhos vazanteiros entendem por casa? Essas perguntas nos falam da necessidade de se apreender etnograficamente como a categoria "casa" vai se desenhando.

Uma casa, no contexto das famílias de vazanteiros e vazanteiras com as quais convivi, borra distinções exógenas a respeito do que seriam espaços domésticos. Somente para um observador descuidado, os fluxos que compõem uma casa não são amplamente atravessados e constituídos pelas dinâmicas da própria vazante. "Botar uma vazante" implica residir em suas proximidades, conforme observamos acima ao falar das séries de cuidados e relações que uma vazante implica para os vazanteiros que as cultivam. A produção das vazantes, nesse sentido, alimenta não apenas os corpos de quem a lavra, mas a própria casa, que só floresce graças a esses cultivares. Na trajetória de diversas famílias de vazanteiros e vazanteiras residentes na Avenida Boa Esperança, os processos de construir uma casa e cultivar na vazante fazem parte de um único movimento, a saber, habitar - na perspectiva proposta por Ingold (2000) - às margens do rio Parnaíba. O que implica estabelecer relações com esse ambiente. Perceber suas nuances. Transformá-lo, deixar registros duradouros por onde passa e, ao mesmo tempo, moldar a si mesmo através dessas interações.

A casa, portanto, é (também) vazante. Mas não só no sentido de que as casas englobam as vazantes (ou mesmo o contrário). Não se trata de uma relação de continência (apenas). Antes disso, casa deve ser entendida como um complexo amplo e aberto o suficiente para incluir a presença dos cultivos da beira do rio, dialogar com os fluxos e ritmos das temporalidades de cheia, vazante, inverno, verão. Deve, ainda, lidar com as dinâmicas dos seres não viventes (como a própria lama), bem como das vidas de pombos, capivaras, quiabos e outros legumes.A casa, assim, desenha-se como um agregado de relações multi específicas. Ela não se constitui na negação disso, pelo contrário: é exatamente a presença de uma diversidade de bichos, plantas e cultivos que, por excelência, define e diz como se faz uma casa nas vazantes. Uma casa vazanteira.

Para a antropóloga Anna Tsing (2015a: 177) a casa é o lugar onde todas as dependências intra e interespecíficas atingem a intensidade máxima. Essa autora argumenta o quanto o projeto colonial buscou constituir a casa como um reduto de pureza e higiene protegido do ambiente externo e, sobretudo, de "outros" 
potencialmente nocivos. Esses outros marcaram não só os limites da humanidade, mas, também, da própria raça branca - no contexto da colonização -, forjando assim sujeitos que deveriam ser domesticados, dominados ou, muito frequentemente, exterminados. A lógica presente nesse viés analítico é a da dominação e excepcionalidade humana. Isso pouco nos fala das relações de interdependência e contaminação entre as diversas espécies que compõem o mundo. A torção metodológica de Anna Tsing, por sua vez, nos permite olhar para contextos como esses, por exemplo, captando aquilo que é negado internamente e nos fazendo acompanhar a tessitura do que seria, talvez, uma "casa multiespécie". Admito que falar assim - "casa multiespécie" -, a partir do diálogo com vazanteiros e vazanteiras com quem convivi, é - absolutamente - uma redundância.

Casa, nesse contexto, é um lugar familiar não só para pessoas, mas também para um sem número de animais e plantas. Os cachorros de dona Davina dividem e empreendem práticas de habitação no ambiente doméstico juntamente com ela e sua família humana. As flores do seu jardim habitam com formigas, pequenos besouros e outros insetos. São ainda acompanhadas por capins periodicamente cortados por suas filhas. Diversos viventes, portanto, compõem o que seria uma casa no universo da Boa Esperança. Além disso, convém destacar todo o complexo espacial significado por uma casa. Ele compreende bem mais do que a área edificada das habitações.

Conforme pontuei anteriormente, parte indissociável das casas na Avenida Boa Esperança são seus quintais. É lá onde se pode sentar com familiares e amigos, cultivar hortas, estender roupas para secar, colocar as crianças para brincarem, amarrar os cachorros na sombra de alguma árvore. Planta-se de tudo um pouco. O quintal não é parte externa da casa, mas constituinte dela. Contíguas ao quintal, há as vazantes, onde dona Davina e seus vizinhos e vizinhas vazanteiras cultivam legumes tanto para o consumo doméstico, quanto para comercialização.

As vazantes dialogam com o ambiente da casa de múltiplas formas, pois cultivar uma vazante implica em residir nas suas proximidades. É preciso cuidar dos cultivares, irrigando-os periodicamente e colhendo os vegetais no tempo certo, atentando para a terra e suas transformações durante o inverno e o verão. Ainda que estejam mais próximas da beira do rio do que das casas, sem casas não há vazantes, como bem me ressaltou seu Valdir. Primeiro por conta dos cuidados que as vazantes requerem, depois porque são nesses ambientes onde parte dos alimentos do cardápio doméstico são 
cultivados.Pensar as casas de vazanteiros e vazanteiras na Avenida Boa Esperança, portanto, implica considerar isso, mas não só.

Ingold (2000), ao definir sua dweeling perspective, nos fala de processos de interação e engajamentos entre organismos e os meios que os constituem. Trata-se de uma relação de mão dupla a partir da qual as pessoas e outros seres vão deixando registros duradouros nos lugares por onde passam. Seguindo esse raciocínio, Ingold (2000: 95) argumenta que os humanos não habitamos em mundos construídos por nós para tal fim, mas, antes disso, "construímos nos mundos em que habitamos". Na Avenida Boa Esperança, casa e vazante fazem parte de um mesmo processo de habitação nas margens do rio Parnaíba. Foi a partir dos agenciamentos para a construção de uma casa e cultivo de legumes que vazanteiros e vazanteiras começaram seus engajamentos com as terras e outros viventes da região. Tal como observamos no caso da família de dona Davina. É neste sentido que habitar uma casa para os meus/minhas interlocutores/as, implica algo além do que residir em alguns metros quadrados de área construída. Envolve um engajamento profundo entre as pessoas, seus ambientes, as múltiplas formas de vida aí presentes e todo o território ribeirinho no qual a Avenida está contida. É basicamente isso que recentes políticas de urbanização desconsideraram sistematicamente.

\section{Uma casa pelo Programa Lagoas do Norte}

As obras do Programa Lagoas do Norte foram iniciadas no início dos anos dois mil. Elas afetam, direta e indiretamente, mais de noventa mil pessoas (Coelho Pereira, 2017). O que corresponde a cerca de dez por cento da população da cidade. O número de famílias a serem desapropriadas com a execução do programa não é menos dramático. Para a execução da área 1 (ver figura 1), cerca de quinhentas famílias foram reassentadas (Teresina, 2015: 3). Na área 2, esse número praticamente quadruplicou, chegando a mais de dois mil (Teresina, 2014b). De acordo com dados levantados pelo Centro de Defesa Ferreira de Sousa - associação de moradores criada em reação às desapropriações empreendidas pelo PLN - estima-se que pelo menos três mil e quinhentas famílias terão sido forçadamente desterradas até o final das obras do programa, prevista para dois mil e vinte e um. 
Figura 1 - Bairros atingidos pelo Programa Lagoas do Norte. Imagem com adaptações do autor.

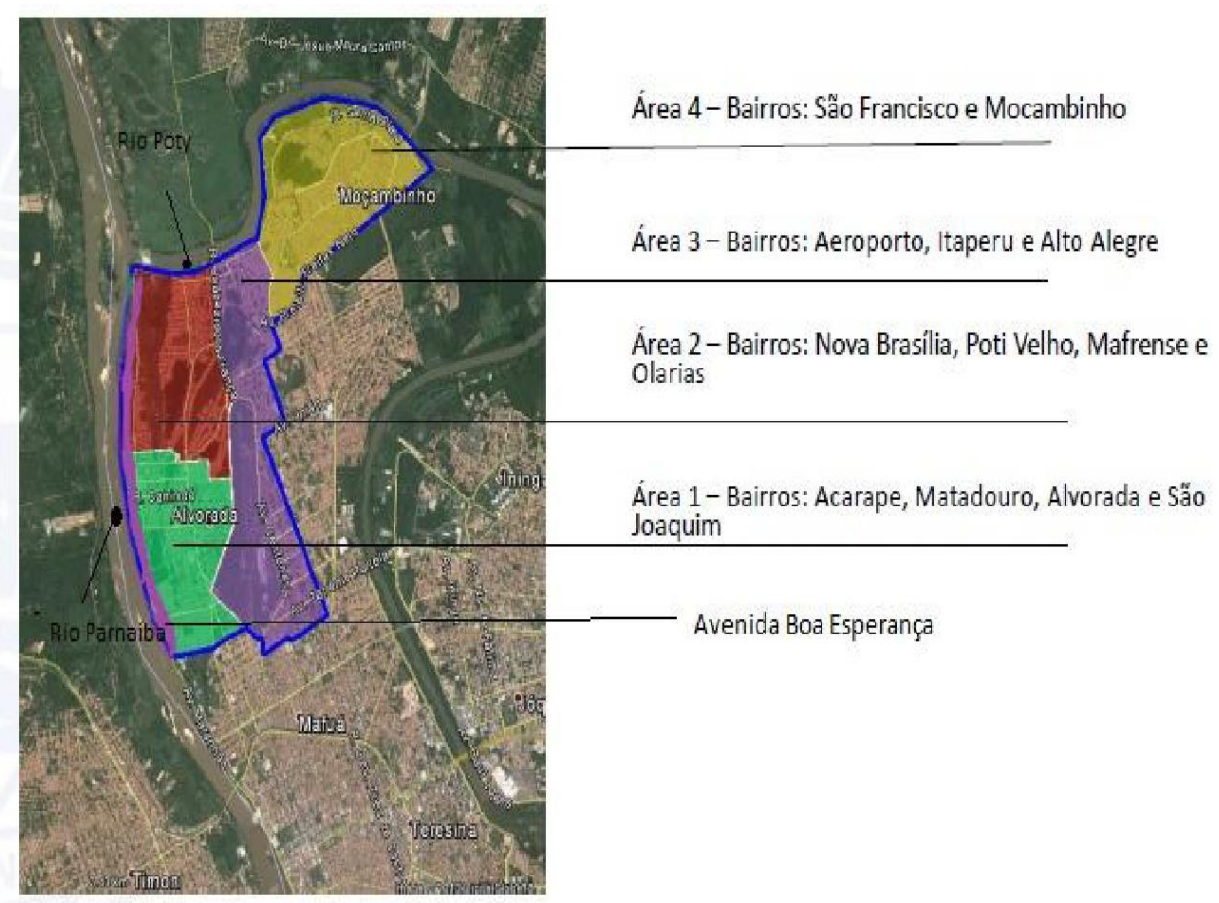

Fonte: Relatório de Avaliação Ambiental (Teresina, 2007)

A justificativa declarada para estes desterros sistemáticos ancora-se no argumento da "vulnerabilidade ambiental" (Teresina, 2007; 2014) da região da zona norte. Considerada sujeita a enchentes recorrentes e uma série de descaminhos socioambientais, como a ocupação desordenada e irregular do solo, poluição das lagoas e a extração de recursos minerais presentes na região. Isso justificaria uma série de intervenções urbanísticas na área. Mais do que um lugar de pessoas - geralmente consideradas um elemento perturbador ao meio -, a região passa a ser vista como um agregado de planícies aluviais, solos silico-argilosos, jazidas minerais desgastadas e uma grande quantidade de corpos hídricos (Portela, 2005; Moura, 2006). Perpassando estas "constatações", há o desenvolvimento de uma ideia-força constantemente afirmada em narrativas socioambientais a respeito da zona norte: tratar-se-ia de um lugar insalubre, composto por um conjunto de planícies fluviais baixas e, portanto, propício a enchentes frequentes. 
As cheias - intimamente relacionadas com a noção de "vulnerabilidade ambiental" da região das Lagoas do Norte - são agentes presentes desde as narrativas de fundação da cidade (primeira metade do século XIX) até os Relatórios de Avaliação Ambiental (Teresina, 2007; 2014) emitidos pelo PLN no início dos anos 2000. São as enchentes que nestes documentos, basicamente, configurariam a região da Avenida Boa Esperança como "área de risco". A partir da retórica do risco, portanto, são engendrados "reassentamentos involuntários" (leia-se: expulsão) dos moradores locais para regiões cada vez mais distantes de uma série de equipamentos públicos urbanos. Por outro lado, na perspectiva das famílias vazanteiras, é somente a partir da relação com as águas que a vida se faz possível, sobretudo, no interior das casas. Complexo que conecta, a partir de si, uma série de outros espaços, como os quintais e as vazantes - conforme observamos anteriormente

$\mathrm{Na}$ tentativa de sanar antigas demandas dos moradores (como melhoria das condições habitacionais, do sistema viário local, da rede de tratamento de esgotos e da coleta de lixo, por exemplo), a Prefeitura Municipal de Teresina em parceria com o Governo Federal através do Programa de Aceleração do Crescimento (PAC) e financiada pelo Banco Mundial apresenta as remoções involuntárias do povo da zona norte. Este seria o primeiro passo na execução de ações supostamente preocupadas com a questão ambiental e qualidade de vida dos moradores locais.

No lugar das vazantes e casas que seguem sendo demolidas, o Programa tem construído parques lineares voltados ao lazer e ao turismo. A futura destinação turística da região da Boa Esperança - concebida como área de esportes e lazer para a contemplação de "belezas naturais" - é algo pública e abertamente declarado, não somente nas falas de gestores (Monte, 2016; Coelho Pereira, 2017), mas em cartilhas explicativas do Programa (Teresina, 2015). Estas obras só se tornam possíveis com a expropriação territorial de boa parte das famílias residentes na região da Boa Esperança a partir dos "reassentamentos involuntários". Prática vivenciada por vazanteiros e vazanteiras com quem conversei como uma ação perpetradora de mortes, uma vez que inviabiliza meios e condições de existência tradicionalmente experienciadas.

Em 2014, a Prefeitura Municipal de Teresina começou a selar/ cadastrar casas.Moradores/as da Avenida Boa Esperança receberam com espanto, indignação e raiva essa atitude do poder público municipal. Sabiam apenas que esta era mais uma das ações do Programa Lagoas do Norte (PLN). 
Quando os habitantes do lugar se depararam com agentes municipais adentrando suas casas com trenas a medir o imóvel e uma câmera fotográfica a fazer imagens dos cômodos, muitas donas de casa se desesperaram. Perguntaram a si mesmas e às vizinhas quem seriam aquelas pessoas, o que queriam de fato e o que significava aquele adesivo fixado atrás das portas dianteiras de suas residências.Ninguém sabia ao certo do que se tratava, nem mesmo o poder público municipal dava explicações cabíveis à entrada de seus funcionários na casa das pessoas. Lúcia Sousa, moradora da zona norte, ex vicepresidente da Associação de Vazanteiros e presidente do Centro de Defesa Ferreira de Sousa disse certa vez que:

- [A prefeitura] adentrou as nossas casas de uma forma muito violenta, porque ela chegou nas nossas casas de manhã, pela manhã! Em um horário que só tinha crianças e idosos! Selou as nossas casas e foi perguntando pras pessoas se as pessoas queriam uma casa ou um apartamento. [grifo meu].

O "selo de congelamento" - no qual consta o número da residência nos arquivos municipais e o símbolo da prefeitura - informa tanto ao/a morador/a como aos/as vizinhos/as que aquele imóvel já fora analisado pelo poder público municipal e que qualquer alteração estrutural feita nele após esta adesivagem não entraria no cálculo da indenização a ser paga para a família passível de ser desalojada. O selo - geralmente fixado atrás da porta de entrada das residências - não significaria, portanto, a inevitável desapropriação do imóvel, conforme informa Monte (2016) baseada em entrevistas com funcionários da prefeitura. Contudo, vale ressaltar a seguinte constatação: se o selo não é sinônimo de um "reassentamento involuntário" inconteste, ele é, pelo menos, o anúncio da possibilidade real de demolição da casa. Além disso, a pergunta "você vai querer casa ou apartamento?", aciona formas de habitar completamente distintas daquelas gestadas nas vazantes da Avenida Boa Esperança. Que tipo de casa o Programa Lagoas do Norte (PLN) oferece às famílias desapropriadas ou em vias de desapropriação? Que noções de casa, em última instância, são acionadas a partir disso?

O PLN oferece, no lugar das residências das famílias vazanteiras desapropriadas, algumas formas de compensação. De acordo com um dos marcos de reassentamento do programa - realizado para a fase 2 , que compreende a área onde está situada a maioria das vazantes da Avenida Boa Esperança - as "opções" disponíveis para as famílias a serem desterradas são: “(i) reassentamento em residencial a ser construído, (ii) inclusão em programas habitacionais existentes, (iii) indenização e (iv) reassentamento 
monitorado." (Teresina, 2014c).Ao "optar" pela indenização, as famílias recebem em dinheiro um valor atribuído ao seu antigo imóvel para que possa efetuar a compra de outra residência em condições semelhantes à sua moradia de origem. Contudo a indenização só pode ser escolhida para quem possuir imóveis avaliados em valores acima de $\mathrm{R} \$ 61.000,00$ reais, o valor do imóvel do residencial a ser construído.

O reassentamento monitorado ocorre quando o imóvel avaliado é inferior ao valor de sessenta e um mil e a casa nos residenciais a serem construídos não atende às necessidades da família. Neste caso, o grupo familiar irá buscar no mercado imobiliário por uma nova moradia e terá incentivo financeiro do programa para tanto. Excetuandose essas duas opções de reassentamento - onde as possibilidades de residir na beira do rio são de partida inexistentes - relembro a pergunta repetida pelas assistentes sociais do programa às famílias de vazanteiros e vazanteiras: casa ou apartamento?

As casas em residenciais disponibilizadas pelo programa são fruto de parcerias técnico-financeiras com a Caixa Econômica Federal através do programa "Minha casa, minha vida". A tipologia das casas oferecidas obedece ao padrão de $41 \mathrm{~m}^{2}$ e os apartamentos construídos de $43 \mathrm{~m}^{2}$. Assim, os conjuntos habitacionais a serem edificados para as famílias reassentadas - no caso de os grupos domésticos não serem encaminhados para programas habitacionais já em vigor - contará com dois tipos de tipologias habitacionais: casa e apartamento (Teresina, 2014c) A primeira seria prioritariamente destinada às famílias mais numerosas, ao passo que a segunda ficaria para famílias pequenas. Tanto em um caso como no outro, a casa é entendida apenas como uma área construída.

A expressão exata dos metros quadrados da residência não é mero detalhe técnico. Ela fala de uma concepção de casa unicamente concebida como espaço para moradia. Nesse documento (e em todos os outros emitidos pelo programa também, vide Coelho Pereira, 2017), não se cita, por exemplo, a possibilidade da existência de quintais e, menos ainda, das próprias vazantes. As casas dos conjuntos habitacionais (construídos e a serem construídos), portanto, não atendem às especificidades sócioculturais e residenciais de famílias ribeirinhas que vivem dos plantios plantados na beira do rio. Elas foram planejadas a partir de princípios e lógicas que desconsideram as diferenças culturais que pautam os modos de vida e existência dos sujeitos alvo dos reassentamentos. Desconsideram, por fim, que - no caso de vazanteiros e vazanteiras uma casa não se faz apenas com tijolos, concreto, telhas e pessoas. Mas, sim, graças a 
uma assembléia de humanos e outros viventes: como cães, gatos, papagaios, criações de pequenos animais, flores, plantas, quiabos e diversos fluxos de vida (INGOLD, 2015) que conectam casas e vazantes numa única malha.

Neste cenário, a desapropriação dos lugares de morada de boa parte dos habitantes da Boa Esperança através do Programa Lagoas do Norte - e aqui falo especificamente de vazanteiros e vazanteiras - é também uma desapropriação dos seus lugares de trabalho, dos seus modos de reprodução social e material - se quisermos pensar por esta chave - mas, também, é a quebra de vínculos e de formas particulares de se engajar com o ambiente e, portanto, de se constituir enquanto pessoa na interação com as águas, a terra, os legumes e todos os outros não-humanos que - em parceria com os humanos - co-habitam as vazantes do lugar.

Analisando a política das desapropriações a partir das conversas com vazanteiros e vazanteiras da Avenida Boa Esperança, primeiro o Programa tira as pessoas das suas casas, ou seja, "escarra-aspara bem longe". Depois disso, "acabar com as vazantes é moleza", disse-me um vazanteiro. Paulatinamente, portanto, sob a justificativa do risco, vazanteiros/as vão sendo forçados a abandonar seus locais de vida e trabalho.

\footnotetext{
- Criei essa família todinha trabalhando de vazante e pescando... A gente chegou nesse lugar sem nada e - depois de ter arrumado alguma coisa nesses trinta anos - ter que mudar para outro lugar, começar de novo, do zero, ir cuidar de outra vida... Não tem condição! Porque aqui, se chegarem a me tirar daqui, pra onde eu ir eu vou começar do zero e já na minha idade! Tem condição um negócio desses? Porque muda [de planta], nem que seja pra colocar de bem daqui pra bem ali, ela tem que murchar. Pode pegar qualquer planta, mesmo que ela esteja naquelas estufas... Corta da estufa, depois pegue ela e bote no chão que ela ainda sente! Assim como é tirar uma pessoa daqui pra botar ela em qualquer lugar que seja. Não é fácil pra gente falar isso... (Seu Valdir)
}

A conversa sobre a planta diz respeito a um processo de constituição mútua entre humanos, não humanos e seus ambientes. Retirar uma muda de um local para replantála em outro implica em um processo de dor, adoecimento e re-adaptação deste ser a um novo lugar que, não raro, pode levá-la a morte. A planta sente. Nisso reside a dificuldade de começar de novo, do zero, ir cuidar de outra vida. Deve-se, portanto, considerar a luta que é se constituir em interação com um novo mundo quando a muda só se fez planta a partir da relação com o meio do qual fora retirada.

\section{Considerações finais}


O caso das famílias de vazanteiros e vazanteiras da zona norte de Teresina fornece material etnográfico para pensarmos conflitos territoriais e socioambientais urbanos a partir da noção de casa. Neste contexto essa categoria fala de um complexo espacial que engloba, também, as vazantes cultivadas na beira do rio e, com elas, a multiplicidade de viventes que as habitam. Cultivar uma vazante implica residir em suas proximidades assim como erguer e se engajar na feitura de uma residência - para meus interlocutores vazanteiros - trata-se de uma ação realizada em paralelo ao cultivo de legumes. São dois processos de um único movimento: habitar um lugar na Avenida Boa Esperança.

Uma casa nas vazantes - uma casa vazanteira - extrapola o ambiente da área construída e inclui os quintais e vazantes cultivadas nas margens do rio Parnaíba. Engloba ainda uma multiplicidade de seres para além dos humanos, como gatos, cachorros, cabras, papagaios, roseiras, quiabeiros, feijoeiros e um sem número de outras plantas. Longe de ser um espaço apartado de outras formas de vida, o complexo casavazante só se constitui a partir do entrelaçamento de diversos organismos. Habitar, assim, implica muito mais do que residir em determinado ambiente, mas, sobretudo, engajar-se com ele de múltiplas formas, gestando-o e gerando a si próprio nestas interações. É nesse sentido que procurei desenvolver a noção de "casa vazanteira", atentando para como bichos, plantas, humanos e plantações são partes constituintes do que se entende por "casa" nas vazantes do médio Parnaíba.

O modo de se conceber e construir casa a partir das vazantes, portanto, difere substancialmente daquele engendrado por políticas de urbanização como o Programa Lagoas do Norte, uma parceria público-privada entre Prefeitura Municipal de Teresina e Banco Mundial. Adotando-se a lógica do PLN, casa seria apenas um lugar onde morar, por isso a pergunta "você vai querer casa ou apartamento?", marca o diálogo do Programa com famílias a serem potencialmente expropriadas dos seus espaços de vida. As casas oferecidas, geralmente em conjuntos habitacionais, sequer possuíam quintais.

Um apartamento, por sua vez, marcaria de maneira indelével a impossibilidade de vazanteiros e vazanteiras continuarem suas atividades agrícolas. O que se oferta no lugar das casas a serem demolidas, portanto, é algo aquém do que "casas de verdade" significam para meus interlocutores. Não se trata apenas de tijolos, telhas e argamassa, mas lugares a partir dos quais a trajetória de vida dos seus habitantes vai sendo tecida na interação com uma multiplicidade de outros viventes.Além disso, ressalto o quanto a 
incomensurabilidade entre o que seria uma casa na perspectiva de vazanteiros e vazanteiras e uma casa ofertada pelo Programa Lagoas do Norte anda junto com uma diferença crucial na forma como a relação das pessoas com o lugar é percebida.

As cheias, consideradas a principal justificativa dos reassentamentos involuntários, ocupam um lugar central na dinâmica agrícola do cultivo das vazantes e, consequentemente, no modo através do qual a Avenida é habitada a partir desses ambientes. Somente atentando para as relações travadas no binômio casa-vazante é que o ritmo das águas, do inverno, do verão e da constituição das próprias casas podem ser consideradas. Prefigurando, assim, o que seria uma casa vazanteira, isto é, uma casa permeada por um conjunto de relações multiespécies. Casa, assim, pode ser pensada, ainda, na perspectiva proposta por Ingold (2015:220): como um lugar onde as linhas de vida dos seus habitantes estão fortemente atadas, mas nem de longe estão contidas nela, pois se emaranham em malhas bem mais amplas e complexas. No caso em tela, esses fios também tecem vazantes e se enovelam com múltiplos viventes além dos humanos.

\section{Referências}

ALMEIDA COSTA, João Batista; Luz de Oliveira, Cláudia. Cerrado, gerias sertões: comunidades tradicionais nos sertões roseanos.São Paulo SP: Editora Intermeios, 2012

AMORIM, Alexandre Nojoza. Etnobiologia da comunidade de pescadores artesanais urbanos do bairro Poti Velho. Teresina/PI, Brasil. Dissertação (Mestrado em Desenvolvimento e Meio Ambiente) - Universidade Federal do Piauí, Teresina, 2010.

ANAYA, FelisaCançado. De "encurralados pelos parques" a "vazanteiros em movimento": as reivindicações territoriais das comunidades vazanteiras de Pau Preto, Pau de Légua e Quilombo da Lapinha no campo ambiental. Tese (Programa de PósGraduação em Sociologia) - Universidade Federal de Minas Gerais, Belo Horizonte, 2012.

BOAS, F. Antropologia cultural. Org. Celso Castro. Rio de Janeiro: Jorge Zahar, 2004.

BOURDIEU, Pierre. A casa kabyle ou o mundo às avessas. Cadernos De Campo, 8(8): 147-159, 1999.

BRANDÃO, Carlos Rodrigues. $O$ afeto da terra: imaginários, sensibilidades e motivações de relacionamentos com a natureza e o meio ambiente entre agricultores e criadores sitiantes do bairro dos Pretos, nas encostas paulistas da serra da Mantiqueira, em Joanópolis. Campinas, SP: Editora da Unicamp, 1999.

BRUM, Ceres Karam; VILAR, Marta Rosales. Apresentação do Dossiê "A casa: deslocamentos, temporalidades e habitabilidades". Século XXI: Revista de Ciências Sociais, [S.1.], v. 8, n. 3, p. 817-822, 2019. 
CARMO, Francisca Danielle Soares do. Povos de terreiro no contexto de intervenções urbanísticas: territórios sociais de religiosidades de matrizes africanas na zona norte de Teresina-PI e o Programa Lagoas do Norte - PLN. Dissertação (Programa de PósGraduação em Sociologia) - Universidade Federal do Piauí, Teresina, 2017.

CARMO, Francisca Danielle Soares do; MORAES, Maria Dione Carvalho de. 2016. Territórios Sociais de Povos de Terreiro em Teresina - PI (consensos e dissensos no processo de intervenção urbanística do Programa Lagoas do Norte, na zona Norte da cidade). In: $30^{\circ}$ REUNIÃO BRASILEIRA DE ANTROPOLOGIA. Anais [...] João Pessoa: Universidade Federal da Paraíba, 2016.

CASTRO, Vonínio Brito de; BARROS; Flávio Bezerra ; MARÍN, Rosa Elizabeth Acevedo;RAVENA, Nírvia. Os vazanteiros, a agricultura de vazante e as barragens da destruição no Médio rio Tocantins: perspectivas etnoecológicas. Estudos Sociedade e Agricultura, vol. 26, n. 1, p. 65-102, 2018.

CASTRO, Vonínio Brito de. A chegada das barragens e as transições nos modos de vida de "vazanteiros-pescadores" do Médio rio Tocantins. Tese (Programa de PósGraduação em Antropologia) - Universidade Federal do Pará, Belém, 2017.

CENTRO DE DEFESA FERREIRA DE SOUSA. Comunidades de Terreiro e o Programa Lagoas do Norte: Notas sobre a ameaça de remoção de terreiros da zona Norte de Teresina-PI. Teresina: manuscrito, 2016.

COELHO PEREIRA, Lucas. Os reis do quiabo: meio ambiente, interveções urbanísticas e constituição do lugar entre vazanteiros do médio Parnaíba em Teresina-Piauí. Dissertação (Programa de Pós-Graduação em Antropologia Social). Brasília: Universidade de Brasília, 2017.

COSTA FILHO, Aderval. Os gurutubanos: territorialização, produção e sociabilidades de um quilombo norte mineiro. Tese (Programa de Pós-Graduação em Antropologia Social) - Universidade de Brasília, Brasília, 2008.

DIEGUES, Antônio Carlos; ARRUDA, Reinaldo Sérgio Vieira. Saberes tradicionais e biodiversidade no Brasil. Brasília: Ministério de Meio Ambiente, 2001

EVANS-PRITCHARD, Edward Evan. Os nuer: descrição do modo de subsistência e das instituições políticas de um povo nilota. São Paulo: Editora Perspectiva, 1978.

HARAWAY, Donna. The companionspecies manifesto: dogs, people, andsignificantotherness. Chicago: PricklyParadigm Press, 2003.

HARAWAY, Donna.When speciesmeet. Londres: Universityof Minnesota Press, 2008.

INGOLD, Tim. The perceptionoftheenvironment: essaysonlivelihood, dwellingand skill. London: Routledge, 2000.

INGOLD, Tim. Human worlds are culturallyconstructed: againstthemotion (I). In: INGOLD, Tim. (Ed.) Key debates in anthropology. London: Routledge, 81-106, 1996.

INGOLD, Tim. Estar vivo: ensaios sobre movimento,conhecimento e descrição.Petrópolis, RJ: Vozes, 2015.

LÉVI-STRAUSS, Claude. 1957. “Tristes trópicos”.São Paulo: Anhembi, 1957 
LIMA, Antônia Jesuíta. Favela COHEBE: uma história de luta por habitação popular. Teresina: EDUFPI; Recife: Bagaço, 2010.

LITTLE, Paul Elliot. Territórios sociais e povos tradicionais no Brasil: por uma antropologia da territorialidade. Série Antropologia/322. Brasília: Universidade de Brasília, 2002.

LITTLE, Paul Elliot. Ecologia política como etnografia: um guia teórico e metodológico. Horizontes Antropológicos, Porto Alegre, ano 12, n. 25, p. 85-103, jan./jun. 2006

LOPES, José Sérgio Leite. A ambientalização dos conflitos sociais. Rio de Janeiro: RelumeDumará : Núcleo de Antropologia da Política/UFRJ, 2004

LUZ DE OLIVEIRA, Cláudia. Vazanteiros do rio São Francisco: um estudo sobre populações tradicionais e territorialidades no Norte de Minas Gerais. Dissertação (Programa de Pós-Graduação em Antropologia Social) - Universidade Federal de Minas Gerais, Belo Horizonte, 2005.

MONTE, Catarina Nery. Artesanato ceramista e direitos culturais frente ao Programa Lagoas do Norte no Poti Velho em Teresina-PI: quais diálogos?.Dissertação (Programa de Pós-Graduação em Políticas Públicas). Teresina: Universidade Federal do Piauí, 2016.

MORAES, Maria Dione Carvalho de. Artesanato cerâmico no bairro Poti Velho em Teresina-PI: (rede sociotécnica, agenda pública, empreendedorismo e economia criativa). Monografia de conclusão de curso (Curso de Formação de Gestores Culturais dos Estados do Nordeste) - Universidade Federal Rural de Pernambuco/ Fundação Joaquim Nabuco/ Ministério da Cultura. Recife: UFRPE/ FUNDAJ/ MEC, 2013.

MOURA, Maria Geni Batista de. Degradação ambiental urbana: uma análise de bairros da zona norte de Teresina. Dissertação (Programa Regional de Pós-Graduação em Desenvolvimento eMeio Ambiente) - Universidade Federal do Piauí, Teresina, 2006

NOGUEIRA, Silvia Garcia; SILVA, Renata Nogueira da. A casa timorense e os estudantes do Timor-Leste no exterior. Século XXI: Revista de Ciências Sociais, [S.1.], v. 8, n. 3 , p. $948-972,2019$.

PIERSON, D. O Homem no Vale do São Francisco. Tomo II. Rio de Janeiro: Ministério do Interior/Superintendência do Vale do São Francisco, 1972.

PORTELA, Mugiany Oliveira Brito. 2005. Extração de argila e suas implicações socioeconômicas e ambientais no bairro Olarias, em Teresina. Dissertação (Programa Regional de Pós-Graduação em Desenvolvimento e Meio Ambiente) -Universidade Federal do Piauí, Teresina, 2005.

TERESINA. PREFEITURA DO MUNICÍPIO. SECRETARIA MUNICIPAL DE PLANEJAMENTO.Programa Lagoas do Norte: Cartilha. Teresina: SEMPLAN, 2015

TERESINA. PREFEITURA DO MUNICÍPIO. SECRETARIA MUNICIPAL DE PLANEJAMENTO. Avaliação Ambiental do Programa de Melhoria da Qualidade Ambiental de Teresina - Programa Lagoas do Norte: Relatório de Avaliação Ambiental. Teresina: SEMPLAN, 2017. 
TERESINA. PREFEITURA DO MUNICÍPIO. SECRETARIA MUNICIPAL DE PLANEJAMENTO. Programa Lagoas do Norte: Marco de Reassentamento Involuntário das Famílias e Imóveis Afetados pela Implantação da $2^{a}$ Fase do PLN. Teresina: SEMPLAN, 2014b.

TERESINA. PREFEITURA DO MUNICÍPIO. SECRETARIA MUNICIPAL DE PLANEJAMENTO. Relatório de Avaliação Ambiental e Social - RAAS, 2014. Programa Lagoas do Norte (PLN). Teresina: SEMPLAN, 2014.

TERESINA. PREFEITURA DO MUNICÍPIO. SECRETARIA MUNICIPAL DE PLANEJAMENTO. Marco de reassentamento involuntário das famílias e imóveis afetados pela implantação da2 ${ }^{a}$ fase do PLN. Teresina: SEMPLAN, 2014c.

TSING, Anna. Margens indomáveis: cogumelos como espécies companheiras. Ilha, 17: 177-201, 2015a.

TSING,Anna. The MushroomattheEndofthe World. Onthepossibilityoflifein capitalista ruins.Princeton: Princeton University Press, $2015 \mathrm{~b}$.

VIRGÍLIO, Nathan. "Esses bicho sugam a vida da gente". Relações de criação e cultivo da vida no Góes-CE. Monografia (Curso de Bacharelado em Ciências Sociais com habilitação em antropologia) - Universidade de Brasília, Brasília, 2014.

WOORTMANN, Ellen; WOORTMANN, Klaas. O trabalho da terra: a lógica e a simbólica da lavoura camponesa. Brasília: Editora da Universidade de Brasília, 1997

WOORTMANN, Klaas. Quente, frio e reimoso: alimentos, corpo humano e pessoas. In: Caderno Espaço Feminino, v. 19, Uberlândia, 2008.

Data de submissão: 19 de dezembro de 2020

Data de publicação: 20 de dezembro de 2021 